\title{
Wave Spectral Patterns during a Historical Cyclone: A Numerical Model for Cyclone Gonu in the Northern Oman Sea
}

\author{
Mohammad Nabi Allahdadi', Nazanin Chaichitehrani², Mohammadreza Allahyar ${ }^{3}$, \\ Laura McGee ${ }^{1}$ \\ ${ }^{1}$ North Carolina State University, Department of Marine, Earth, and Atmospheric Sciences, Raleigh, North Carolina, USA \\ ${ }^{2}$ Louisiana State University, Department of Oceanography and Coastal Sciences, Baton Rouge, Louisiana, USA \\ ${ }^{3}$ Iranian Ports and Maritime Organization, Tehran, Iran \\ Email:mallahd@ncsu.edu,nchaic1@lsu.edu, allahyar@pmo.ir,lcmcgee@ncsu.edu
}

How to cite this paper: Allahdadi, M.N., Chaichitehrani, N., Allahyar, M. and McGee, L. (2017) Wave Spectral Patterns during a Historical Cyclone: A Numerical Model for Cyclone Gonu in the Northern Oman Sea. Open Journal of Fluid Dynamics, 7, 131-151. https://doi.org/10.4236/ojfd.2017.72009

Received: April 3, 2017

Accepted: May 8, 2017

Published: May 11, 2017

Copyright $\odot 2017$ by authors and Scientific Research Publishing Inc. This work is licensed under the Creative Commons Attribution International License (CC BY 4.0).

http://creativecommons.org/licenses/by/4.0/ (c) (i) Open Access

\begin{abstract}
The third generation wind-wave model Mike21-SW was used to study spectral characteristics of waves generated by the historical Cyclone Gonu in June 2007 along and off the Iranian coasts on the northern Oman Sea. The model was forced with the cyclone wind field generated using a Holland (1980) model based on cyclone data obtained from the Joint Typhon Warning Center (JTWC). The wave model was calibrated for the northern Oman Sea using bulk and spectral wave data at a station out of the Chabahar Bay. Evolution of directional-frequency spectra during the cyclone was investigated for two locations near the entrance and off the Chabahar Bay. At the offshore station, energy was contributed to the spectrum over an approximately 180 degree directional span that included different local and remotely generated waves. As the cyclone proceeded northwestward, all spectral directions continuously rotated in the clockwise direction at both locations. Frequency spectra at these locations were investigated for four different times corresponding to different locations of Cyclone's eye and were justified using the sea growth parameter of the Joint North Sea Wave Project (JONSWAP) experiment. Using the modified JONSWAP parameters for hurricane conditions resulted in a frequency spectrum consistent with simulation results.
\end{abstract}

\section{Keywords}

Cyclone Gonu, Oman Sea, Chabahar Bay, Wave Modeling, Wave Spectrum, JONSWAP

\section{Introduction}

Tropical cyclones are energetic atmospheric phenomena with complex spatial 
and temporal structures. The ocean's response to cyclones can be even more complex due to many additional oceanographic and fluid mechanics processes interacting with the atmospheric fields. The response is always associated with extreme wave heights, large current velocities, and substantial water level variations (Allahdadi et al. [1]). Furthermore, tropical cyclones substantially contribute to transport of sediments and biogeochemical substances over oceanic and shelf waters (D'Sa et al. [2]; Tehrani et al. [3]; Chiaichtehrani [4]). Wave characteristics are among the most relevant oceanic responses of these storms, due to their destructive effects on structures and coastal communities as well as their substantial effects on transport phenomena in the shelf waters. Extreme wave heights generated by Cyclones are used as the main parameter for designing offshore and coastal structures. The wave height is also used for studying beach erosion which is a common phenomenon during severe storms.

In a random sea, waves are described using energy spectra as a function of frequency and direction. The spectral characteristics of a random sea as a function of frequency during the fair weather condition and regular unidirectional storms were well determined from JONSWAP (Hasselman et al. [5]). The directional distributions of sea waves under these conditions were studied by several researchers including Mitsuyasu [6], Hasselman [7], and Donelan [8].

A pioneer study on the spectral pattern of ocean waves during a hurricane was the study of Whalen and Ochi [9]. They analyzed the measured spectra during hurricanes Camille, Celia, Edith, and Eloise. They found that as a hurricane approaches the recording location, the dominant spectra change from bi-modal (frequency spectrum with two energy peaks) to uni-modal (frequency spectrum with only one energy peak). They confirmed that the spectral patterns of JONSWAP and Ochi-Hubble are appropriate approximations for the uni-modal and bi-modal hurricane-generated spectra, respectively. Ochi [10] stated that the frequency spectra resulting from measurements during hurricanes are different from those of ordinary storms. By comparing spectra of similar severity for ordinary storms and hurricanes, he showed that for a hurricane-generated spectrum, energy is more concentrated around the peak frequency and a narrower spectral range is observed. Using a comprehensive directional wave data set at the location of a buoy off the northwestern Australian coast, Young [11] studied patterns of frequency and directional spectra generated by passing tropical storms. He concluded that although the spectra were composed of both swells and locally generated waves, there was no tendency for the frequency spectra to behave as bi-modal. In addition to the high similarity between the hurricanes' generated frequency spectra and those of uni-directional winds, the parameters for defining the spectra were similar. He suggested that this similarity is the result of the shape stabilization effect controlled by non-linear interaction. According to his results, the shape of the frequency spectra is mainly controlled by non-linear interaction, while the effect of input energy and dissipation is minor.

Studies done by Walsh et al. [12] and Wright et al. [13] were substantial developments in understanding the directional wave spectra produced by hurri- 
canes, especially in close proximity to the hurricane center, where measurement of wave parameters and spectra using moored buoys are sparse. They used the NASA Scanning Radar Altimeter (SRA) aboard one of the NOAA WP-3D hurricane research aircraft to study the directional spectra of surface waves when Hurricane Bonnie (26 August 2006) was passing between Charleston, South Carolina, and Cape Hatteras, North Carolina, and during its landfall near Wilmington, North Carolina. Using this data, Wright et al. [13] studied the open ocean directional spectra and characterized different components of the wave field generated by the hurricane as well as the spatial variations of the spectra. The analysis led to a simple model for estimating the dominant wave propagation direction. The result of the SRA data analysis by Walsh et al. [12] during the hurricane's landfall was surprising since showed a remarkable similarity between the directional spectra of the open ocean and the landfall region. They concluded that the hurricane wave field can be parameterized using a few simple parameters such as maximum wind speed, the radii of maximum wind, and gale-force winds.

Due to their spatial and temporal flexibilities, numerical models are well suited for studying the spectral pattern of waves generated by cyclones (Moon et al. [14]; Kumar and Stone [15]; Zhou et al. [16]; Fan et al. [17]; Kim et al. [18]). Zhou et al. [16] used WAVEWATCH-III simulation results to study wave fields and the spectral variations produced by Typhoon Damrey that passed over the South China Sea in September 2005. By examining directional wave spectra, they found that for distances up to $2 \mathrm{R}$ (where $\mathrm{R}$ is the radius of maximum wind) the directional spreading was larger to the left of the typhoon, while a narrower spreading was observed on the right side. Furthermore, the dominant pattern of the frequency spectra on the right side of the typhoon was uni-modal (one peak) compared to the more complex frequency spectra in the rear and left. The numerical modeling studies mostly focused on just presenting the variations of 1-D or 2-D wave spectra during the cyclones. This paper employs a numerical model to investigate the evolution of wave spectra during Cyclone Gonu in the northern Oman Sea and to evaluate them in terms of analytical spectral patterns. The overarching aim of this study is to describe peaks of frequency spectra induced by Cyclone Gonu using traditional JONSWAP parameters, and examining the consistency between the simulated spectra and a modified representation of the JONSWAP spectrum for hurricane conditions. This study is unique and unprecedented for the northern Oman Sea, especially during Cyclones which are not frequent phenomena in this area. One novel aspect of the study for this area is using spectral data from a coastal buoy to evaluate model performance in simulating wave frequency spectra.

\section{Cyclone Gonu}

A persistent area of convection in the eastern Arabian Sea on 1 June, 2007, turned into a cyclone equivalent to a category 5 hurricane by 5 June as a result of a favorable upper-level atmosphere and an enormous amount of heat flux from 
the warm sea surface. Sustaining a maximum wind speed of $240 \mathrm{~km} / \mathrm{h}$ on 5 June made Gonu the strongest tropical cyclone that had ever occurred in the Arabian Sea. The Cyclone moved northwestward and dissipated after making the first landfall over the eastern tip of Oman on 6 June. The Cyclone then continued its northwestward movement and made the final landfall on the Makran coast of Iran about 150 kilometers east of the Persian Gulf (Najar and Salvekar [19]). Gonu caused the loss of 50 lives in Oman and 28 along the Iranian coasts. The economic damages were about $\$ 4$ billion in Oman and more than $\$ 200$ million in Iran. Figure 1 shows Gonu's track at different times (Mashhadi et al. [20]).

Atmospheric aspects and oceanographic responses to Gonu have been studied by different researchers (Fritz et al. [21]; Krishna and Rao [22]; Dibajnia et al. [23]; Wang et al. [24]; Mashhadi et al. [20]). Dibajnia et al. [23] used the 3rd generation WAVEWATCH-III wave model to simulate the wave field generated by Gonu in the northern Oman Sea and along the Iranian coasts. They used wave data measured out of the Chabahar Bay to evaluate the simulated wave height and period. The simulated wave field was used to modify the database for extreme wave height over the area. In the present study, wave data from the same station outside of the Chabahar Bay (station AW2 in Figure 1) is used for evaluating both parametric and spectral outputs of the Mike21-SW model.

\section{Wind Field Generation}

A parametric model suggested by Holland [25] was applied for the wind field of Cyclone Gonu. This model has been successfully used for simulating cycloneinduced currents, waves, and storm surges (Young and Sobey [26]; Phadke et al.

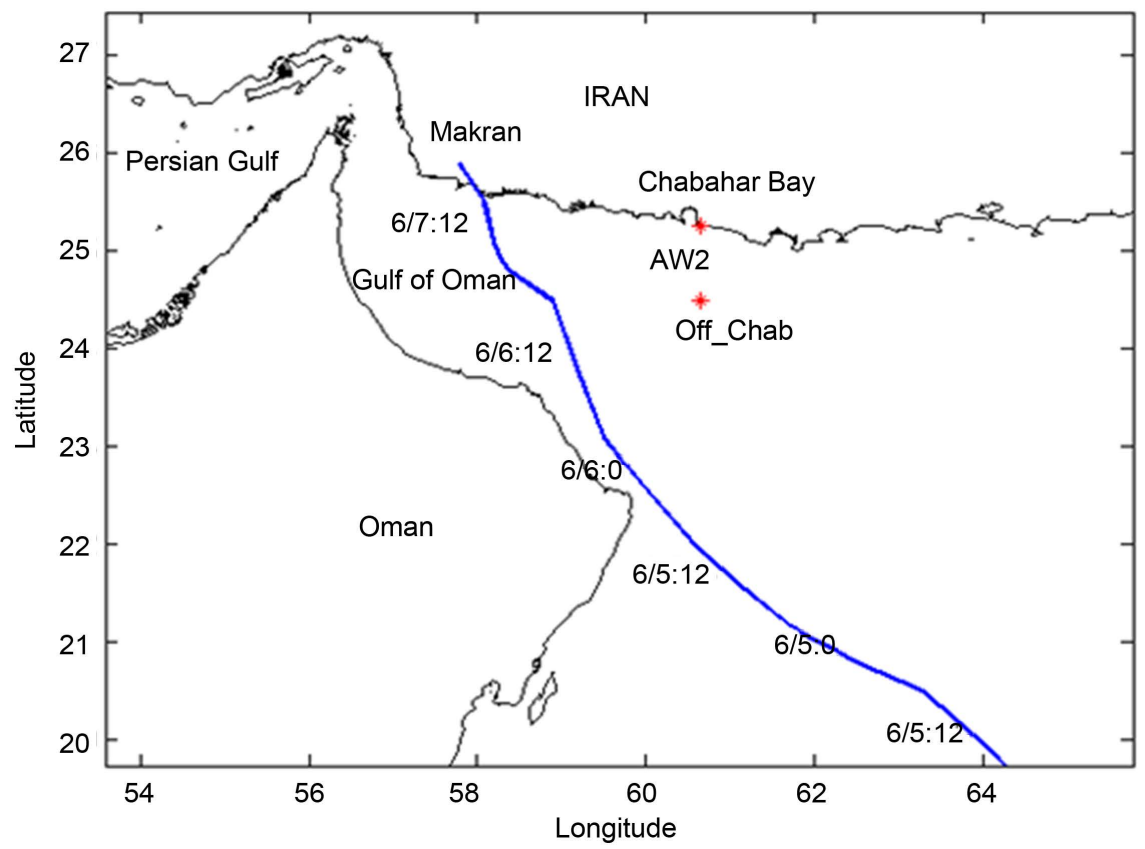

Figure 1. Track of Gonu in the Arabian Sea and Gulf of Oman at different times (time format is month/day: hour). Locations of wave measurement station AW2 and the offshore station Off_Chab are shown with asterisks. 
[27]; Rego and Li [28]; Rego and Li [29]; Allahdadi [30]). This single vortex model uses parameters associated with the Cyclone to re-construct the spatial distribution of wind and air pressure fields. Using $V_{g}(r)$ and $p(r)$ to denote the wind speed and air pressure, respectively:

$$
\begin{gathered}
V_{g}(r)=\sqrt{\left(p_{n}-p_{c}\right) \frac{B}{\rho_{A}}\left(\frac{R_{m w}}{r}\right)^{B} \exp \left(-\frac{R_{m w}}{r}\right)^{B}+\left(\frac{r \cdot f}{2}\right)^{2}}-\frac{r|f|}{2} \\
p(r)=p_{c}+\left(p_{n}-p_{c}\right) \exp \left(-\frac{R_{m w}}{r}\right)^{B} \\
B=2.0-\left(p_{c}-900\right) / 160
\end{gathered}
$$

in which $P_{n}$ denotes the neutral air pressure, $P_{c}$ pressure at the center of hurricane, $R_{m W}$ the radius of maximum wind, $r$ radial distance from the center of the hurricane, $f$ Coriolis parameter, and $\rho_{A}$ air density, respectively.

The data for generation of Cyclone's wind field based on the above formula include: the location of Gonu's center at different times, pressure data at the center of the Cyclone, and natural air pressure. They were obtained at 6-hour intervals from the database for the best track data provided by JTWC. Selecting the radius of maximum wind was challenging. In this study, the approach suggested by Willoughby et al. [31] for hurricanes in the Atlantic basin was used for estimating the radius of maximum wind. The generated wind speed was compared with measurements at AW2 (Figure 2).

Figure 3 shows the generated Cyclone wind field at four different times corresponding to four different locations of the eye when the Cyclone was translating the Arabian Sea and the Gulf of Oman (Table 1). For two locations AW2

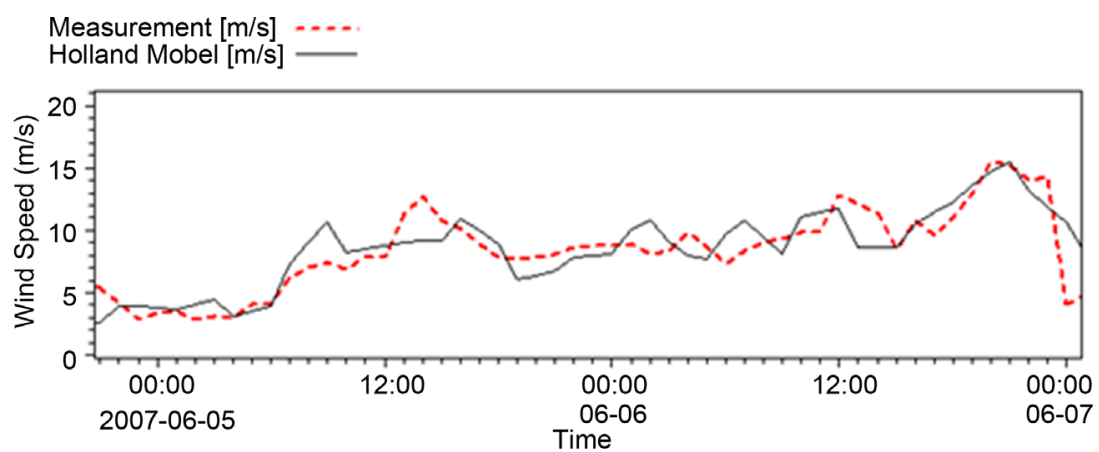

Figure 2. Comparison of generated Gonu's wind speed with measured data at AW2.

\begin{tabular}{|c|c|c|c|c|c|c|c|}
\hline Time & Date and Time & Lon(Eye) & Lat(Eye) & $\mathrm{Xr}$ (AW2) & $\mathrm{Xr}$ (Off Chab) & Uave(AW2) & Uave(Off Chab) \\
\hline Unit & & degree & degree & $\mathrm{km}$ & $\mathrm{km}$ & $\mathrm{m} / \mathrm{s}$ & $\mathrm{m} / \mathrm{s}$ \\
\hline $\mathrm{t} 1$ & $6 / 5 / 2007$ 15:00 & 61.00 & 22.00 & 328 & 252 & 14.3 & 19.2 \\
\hline $\mathrm{t} 2$ & $6 / 6 / 20073: 00$ & 59.00 & 23.00 & 280 & 223 & 17.9 & 21.6 \\
\hline t3 & $6 / 6 / 2007$ 15:00 & 59.00 & 24.00 & 208 & 172 & 12.8 & 16.4 \\
\hline $\mathrm{t} 4$ & $6 / 7 / 20073: 00$ & 58.30 & 25.00 & 236 & 240 & 6.7 & 5.8 \\
\hline
\end{tabular}

Table 1. Geographic locations and Gonu's average radial generated wind speeds at AW2 and Off_Chab for times t1-t4. 

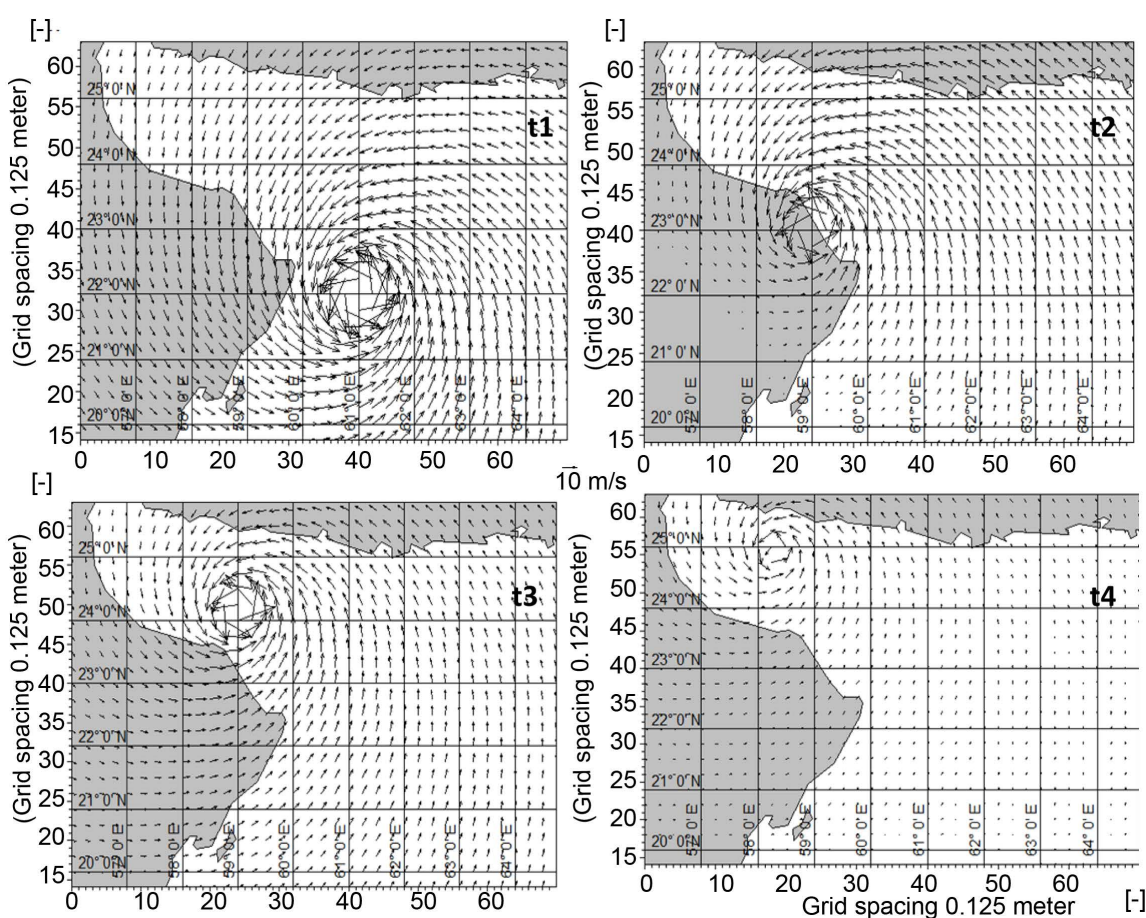

Figure 3. Generated Gonu wind field over the Arabian Sea and northern Oman Sea at different times (labels on $\mathrm{x}$ and $\mathrm{y}$ axis show the Grid number of the wind model. Gridlines show the real longitude and latitude).

and Off_Chab as shown in Figure 1, the distances from Gonu's eye and the average wind speeds along lines between each location and the eye are presented in Table 1. These parameters will be used for further analysis of spectral data.

In this table, $\mathrm{Xr}$ is the distance between Gonu's eye and location of the station for a specific time step and Uave is the average wind speed along this distance.

\section{Model Implementation}

\subsection{Numerical Model}

The 3rd generation wave model Mike21-SW prepared by the Danish Hydraulic Institute (DHI) was applied to simulate waves generated by Gonu. The model solves the wave action density equation in spherical coordinates (DHI [32]):

$$
\begin{aligned}
\frac{\partial \hat{N}}{\partial t}+\frac{\partial}{\partial \phi}\left(c_{\phi} \hat{N}\right)+\frac{\partial}{\partial \lambda}\left(c_{\lambda} \hat{N}\right)+\frac{\partial}{\partial \sigma}\left(c_{\sigma} \hat{N}\right)+\frac{\partial}{\partial \theta}\left(c_{\theta} \hat{N}\right)=\frac{S}{\sigma} \\
\hat{N}=N R^{2} \cos \phi \\
N=\frac{E}{\sigma}
\end{aligned}
$$

where $N$ is wave action density, $E$ is wave energy as a function of relative angular frequency and propagation direction, $\phi$ is longitude, $\lambda$ is latitude, $c_{\phi}$ is wave group velocity in the direction of longitude, $c_{\lambda}$ is wave group velocity in the direction of latitude, $c_{\sigma}$ is wave group velocity in the frequency space, $c_{\theta}$ is the wave group velocity in directional space, $R$ is the radius of the earth, $S$ is the source 
term, and $t$ is time. Source term $S$ is defined as:

$$
S=S_{i n}+S_{n l}+S_{d s}+S_{b o t}+S_{\text {surf }}
$$

This equation includes the effect of input wind energy $S_{i n}$, energy transfer as a result of non-linear wave interaction $S_{n p}$ energy dissipation due to white capping $S_{d s}$, energy dissipation produced by bottom roughness in shallow water areas $S_{b o t}$ and energy dissipation induced by wave breaking in the surf zone $S_{\text {surf }}$ White capping is a process that limits wave growth with wind. The following formulation is used in Mike21-SW for representing the energy dissipation rate due to white capping:

$$
\begin{aligned}
S_{d s}(f, \theta)=-C_{d s}\left(\frac{\hat{\alpha}}{\alpha_{P M}}\right)^{m}\left\{(1-\delta) \frac{k}{\bar{k}}+\delta\left(\frac{k}{\bar{k}}\right)^{2}\right\} \bar{\sigma} E(f, \theta) \\
\alpha_{P M}=\left(3.02 \times 10^{-3}\right)^{1 / 2} \\
\hat{\alpha}=\bar{k} \sqrt{E_{\text {tot }}}
\end{aligned}
$$

In the above equations $C_{d s}$ is the white capping coefficient. The default value for this parameter is 4.5. However, it can be used as a tuning parameter for deep-water waves. Wave period can be partially tuned by changing parameter $\delta$, which has a default value of 0.5 , to variations between 0 and 1 . Parameter $k$ is wave number with the average of $\bar{k}$ while $\bar{\sigma}$ is the average angular velocity. The value of exponent $m$ is assumed 1 following WAMDI group [33]. $E_{\text {tot }}$ represents the total energy of the wave spectrum.

\subsection{Modeling Area and Computational Mesh}

The modeling area includes the northern Indian Ocean from latitude of $24 \mathrm{~N}$, the Oman Sea, Arabian Sea, Oman coast, and Iranian coasts along the northern Oman Sea. The computational mesh is composed of triangular elements with a general refining trend from the southern boundary toward the Iranian coasts. Hence, the lowest resolution of 5000 meters is found along the southern model boundary and the highest resolution of 500 meters is attributed to the Chabahar Bay entrance along the Iranian coast (Figure 4).

\subsection{Model Setup and Calibration}

Different resources were used to obtain the most appropriate model parameters (Table 2). The model time step was obtained based on the Courant stability criterion, which was calculated using model spatial and spectral steps and the maximum wave celerity in the modeling area. Since the main focus of the modeling was the northern Oman Sea, specifically outside of the Chabahar Bay, wave measurements at station AW2 were used for evaluation and tuning simulated wave height and wave period. The process was completed by examining different values of white capping parameters for wave height and wave period as mentioned in section 4.1. Model spectral parameters including number of spectral directions, number of spectral frequencies, and the minimum frequency in model calculations were obtained from literature (Komen et al. [34]; Moon et al. 


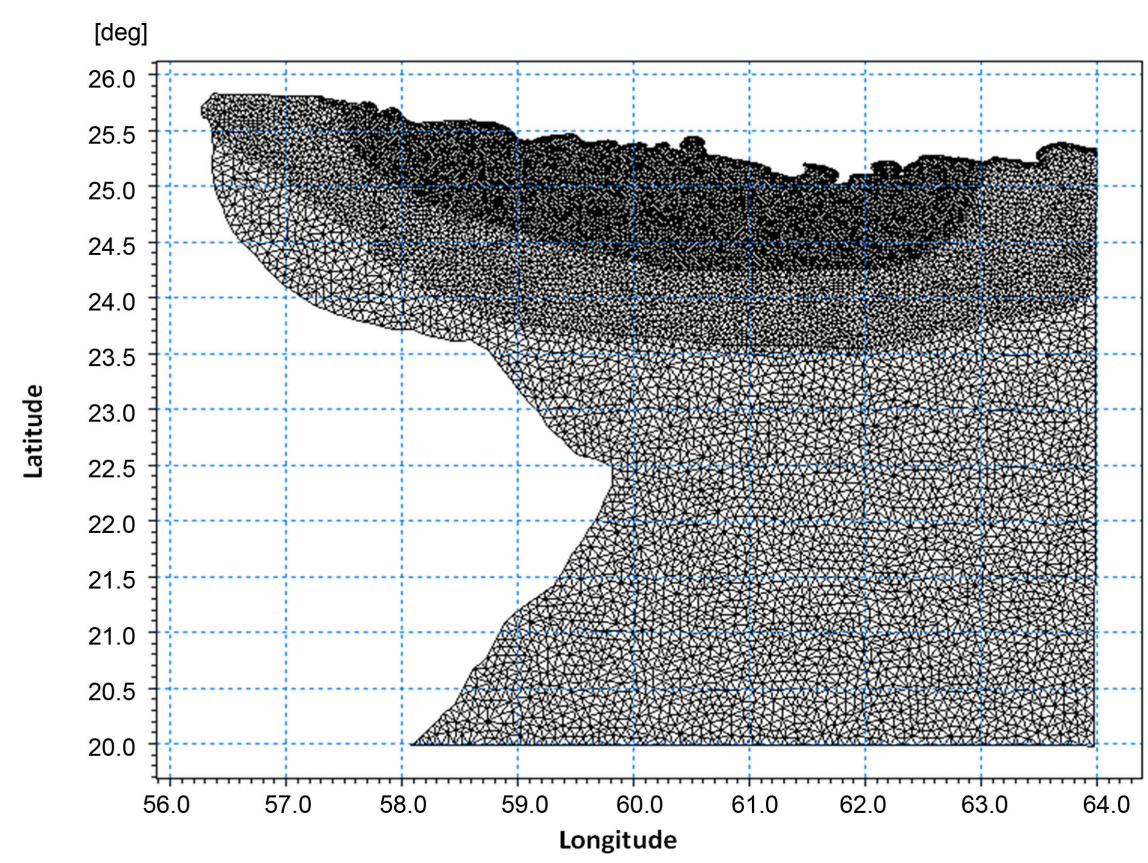

Figure 4. Model computational mesh over the Arabian Sea and northern Oman Sea.

Table 2. Model parameters for simulating Gonu's wave field.

\begin{tabular}{ccccc}
\hline Parameter & Symbol & Unit & Value & Reference \\
\hline Time step & $\Delta t$ & seconds & 100 & Stability criterion \\
White capping & $C_{\text {dis }}$ & - & 6 & Calibration \\
White capping & $\delta$ & - & 0.5 & Calibration \\
Number of spectral directions & $\mathrm{Ndir}$ & - & 40 & Literature \\
Number of spectral frequencies & $\mathrm{Nf}$ & - & 30 & Literature \\
Minimum frequency & $\operatorname{minf}$ & $\mathrm{Hz}$ & 0.025 & Literature \\
\hline
\end{tabular}

[14]; Kumar and Stone [15]; Allahdadi et al. [35]). The final parameters used for the model are summarized in Table 2.

Comparisons of model results with measurements at AW2 for wave height, mean period, and mean wave direction are presented in Figure 5. Using the simulation's wind field and the tuning based on data at AW2, the model could appropriately simulate variations of wave height when the Cyclone was translating the northern Oman Sea. The model simulated almost the same wave height peak of 4.5 meters measured at AW2. In addition to the bulk wave parameters, simulated frequency spectra were compared with measured spectra at two specific times with measured wave heights of 3.5 and 4.5 meters (Figure 6). For both times, the model was able to represent a satisfactory spectral pattern, peak period, and spectral peak value.

\section{Modeling Results and Discussion}

\subsection{Wave Height Variations}

Using the verified generated Gonu wind field and the above wave model specifi- 

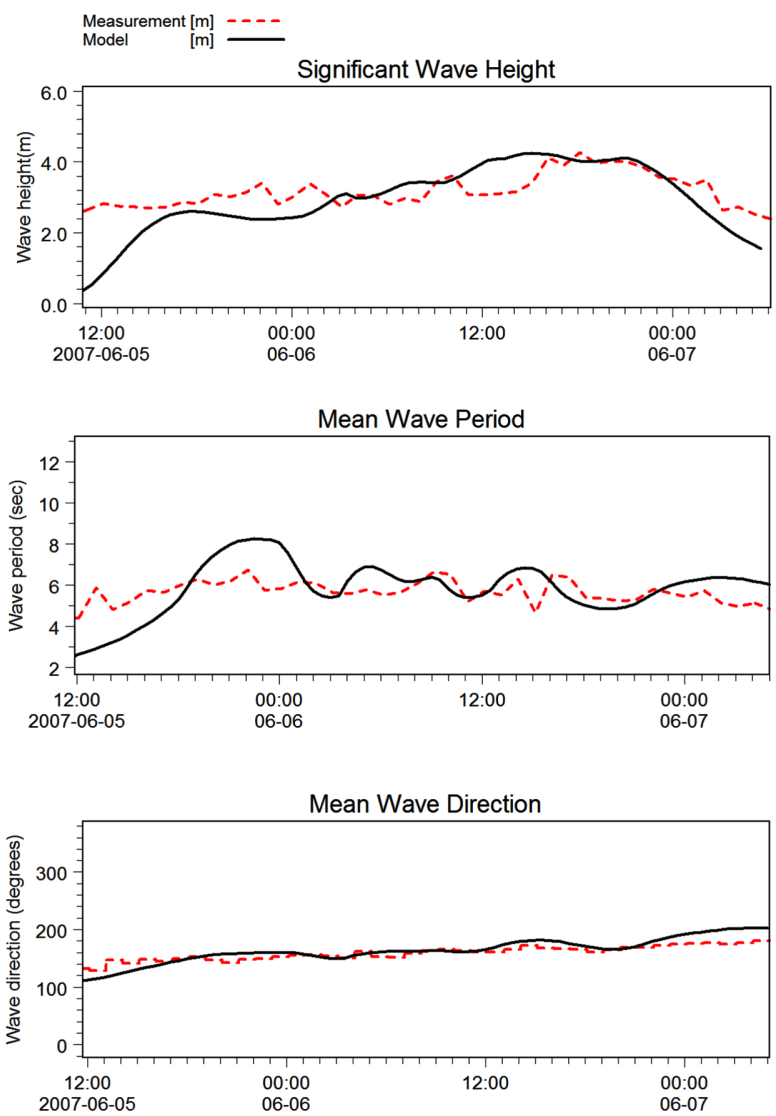

Figure 5. Simulated wave evaluation versus measurements at AW2.
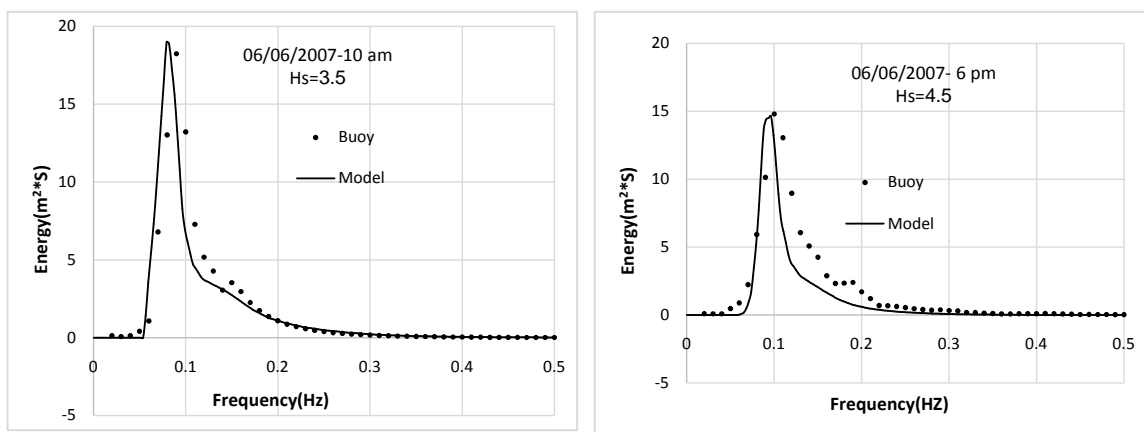

Figure 6. Evaluation of simulated frequency spectrum with measured spectrum at AW2.

cations, the wave model was run from 1 June 2007 to 7 June 2007. Since the focus of this paper is, studying wave spectra characteristics in the northern Oman Sea, simulated wave fields are investigated from 5 - 7 June 2007, when the eye was located between the Oman and Iranian coasts. Figure 7 shows snapshots of the simulated wave height isobars as well as wave vectors. The times corresponding to each panel are consistent with the wind fields shown previously in Figure 3 (t1, t2, t3, and t4). At time t1 (6 June 2007 at 3:00 pm), Gonu's eye was located about $328 \mathrm{~km}$ southeast of the Chabahar Bay entrance and about $120 \mathrm{~km}$ east of the Oman coast. When the eye was far from the Chabahar Bay, the generated waves at the Bay were as small as one meter with southeast direction, 

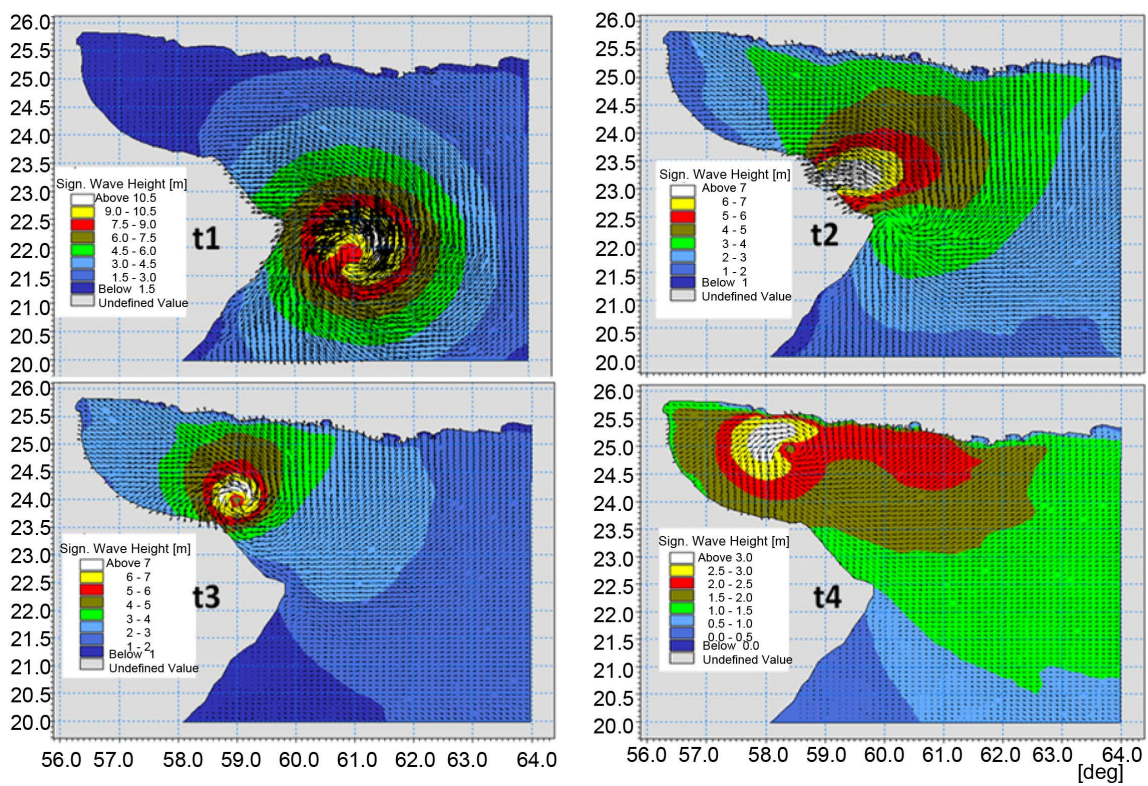

Figure 7. Simulated Gonu's wave field over the Arabian Sea and Gulf of Oman at times t1 to $t 4$.

while the maximum significant wave height close to the eye was over 10 meters. At time t2, the Cyclone's maximum wind speed decreased substantially due to its first landfall along the Oman coast. At this time, the maximum simulated wave height close to the eye was about 7 meters. In spite of the degrading Cyclone, the generated wave height near the Chabahar Bay was larger than time t1 (about 3 meters) due to the northwestward movement of the eye, bringing it closer to the Chabahar Bay $(280 \mathrm{~km})$. The reduced distance was associated with stronger winds at the Chabahar Bay and the propagation of remote cyclone waves from a closer distance. At time t3 (6 June 2007 at 3:00 pm), the eye was in the Gulf of Oman midway between the northern Oman coast and southern Iranian coasts. The distance from the eye and the Chabahar Bay entrance was about $208 \mathrm{~km}$. The maximum wave height generated by Gonu was similar to time $t 2$. Although at this time the eye was closer to the Chabahar Bay, due to the Cyclone's shrinking radius, wave height at the Bay was smaller (about 2.5 meters). At time 44 , just a few hours before the final landfall along the Iranian Makran coast in the northern Gulf of Oman, Gonu's eye was located about $280 \mathrm{~km}$ west of the Chabahar Bay. The weakened Cyclone winds generated a maximum significant wave height of about 3 meters in the Gulf of Oman, while southwestern waves about 2.5 meters in height were observed out of the Chabahar Bay.

\subsection{Frequency-Directional Spectra}

The spectral pattern of Gonu's generated waves is investigated for two locations; AW2 and Off_Chab (see Figure 1 for locations). Figure 8 shows 2-D directional-frequency spectra for location AW2 at times t1-t4. As in Table 1, the distance from this location to Gonu's eye varies between 208 and $328 \mathrm{~km}$, with the farthest distance at time t1. Wave characteristics at these locations can be affected 

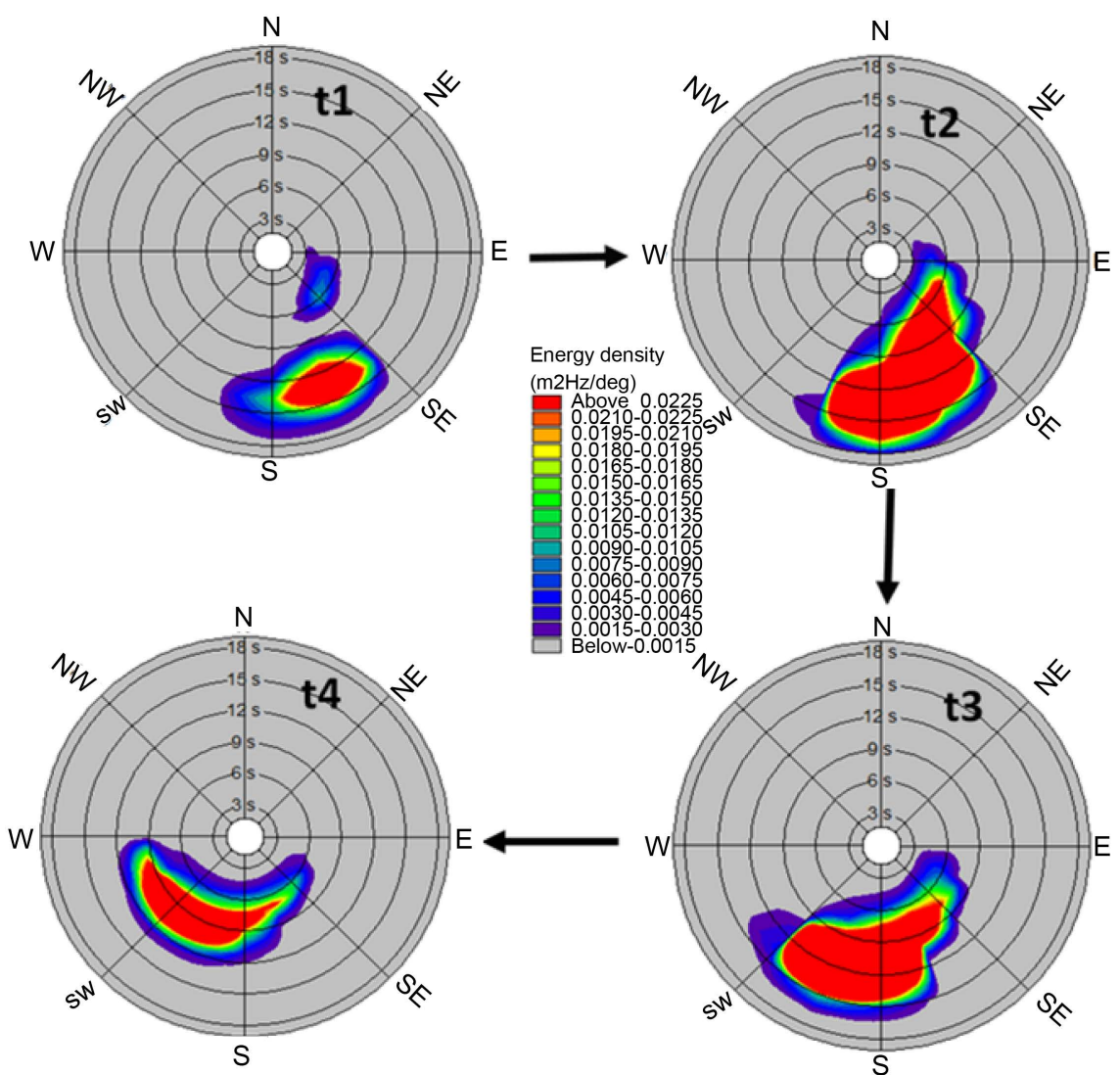

Figure 8. Simulated wave directional-frequency spectrum at AW2 at times t1 to t4.

by local Cyclone-induced winds, remote winds in the proximity of the eye, or their combination. The effect of local and remote winds is clearly seen in the AW2 wave spectrum shown at time t1. While the major part of the wave energy was the relatively low frequency zone confined between the south and southeast sectors (resulting from the remote Cyclone winds), a minor isolated part of the wave energy existed in the high frequency zone (periods less than 6 seconds) with directions between east and southeast. This zone is consistent with the predominant local winds at this time. As the eye moved northwestward, closer to the station location, wave height and spectral energy increased. At time $\mathrm{t} 2$, the low energy part of the spectrum corresponding to local wind evolved to a highenergy zone. The zero energy area between the local and remote spectral energy zones, as seen in time t1, was filled with high energy. Hence, a broad highenergy band covering the directions from east to southeast (with a width of almost 120 degrees) was formed. The fact that the two independent patches of the spectrum at time $\mathrm{t} 1$ were connected at time $\mathrm{t} 2$ and formed a high-energy zone, shows that, closer to the eye, more high energy directions contributed to the wave field due to a combination of remote and local winds. At this time, energy was available for a wide frequency range including periods of 3 to 18 seconds. At time $\mathrm{t} 3$ the general spectral pattern was similar to time $\mathrm{t} 2$. However, due to the changing relative angle of the Cyclone's wind with respect to AW2, spectral directions rotated about 25 degrees clockwise. Furthermore, because of degrading 
Cyclone winds, the maximum spectral period decreased from 18 to 16 seconds. Rotation of spectral directions continued with the northward movement of the eye. At time $t 4$ the rotation was about 30 degrees relative to time $t 3$. Spectral frequencies changed to values corresponding to periods of 5 to 12 seconds. This shrinking was mainly due to the weakening of remote winds around Gonu's eye and a more spatially uniform wind speed. Evolution of wave spectra from time $\mathrm{t} 1$ to time $\mathrm{t} 4$ clearly showed a clockwise rotation of spectral energy (see the black arrows in Figure 8). This rotation occurs because on the right side of a cyclone in the Northern Hemisphere, the wind vector rotates clockwise with time (Allahdadi [30]).

Station Off_Chab is located about 80 kilometers offshore of the Chabahar Bay entrance. The distance between Gonu's eye and this location varies between 172 and $252 \mathrm{~km}$ for times $\mathrm{t} 1$ to $\mathrm{t} 4 \mathrm{with}$ the closest distance corresponding to time $\mathrm{t} 3$. Compared to AW2, a significantly wider range of directions contributes to the spectral evolution of wave energy (Figure 9). The discrepancies can be attributed to the specific location of AW2 along the eastern shoreline out of the Chabahar Bay. The short distance from this location to the shoreline (about $5 \mathrm{~km}$ ) limited wave energy generation from the north and northeast toward this point. At time t1 a wide range of spectral directions, including energy from north to south, composed the energy spectrum at Off_Chab. While the lower frequency (higher period) part of the spectrum is related to the southwesterly and southerly waves
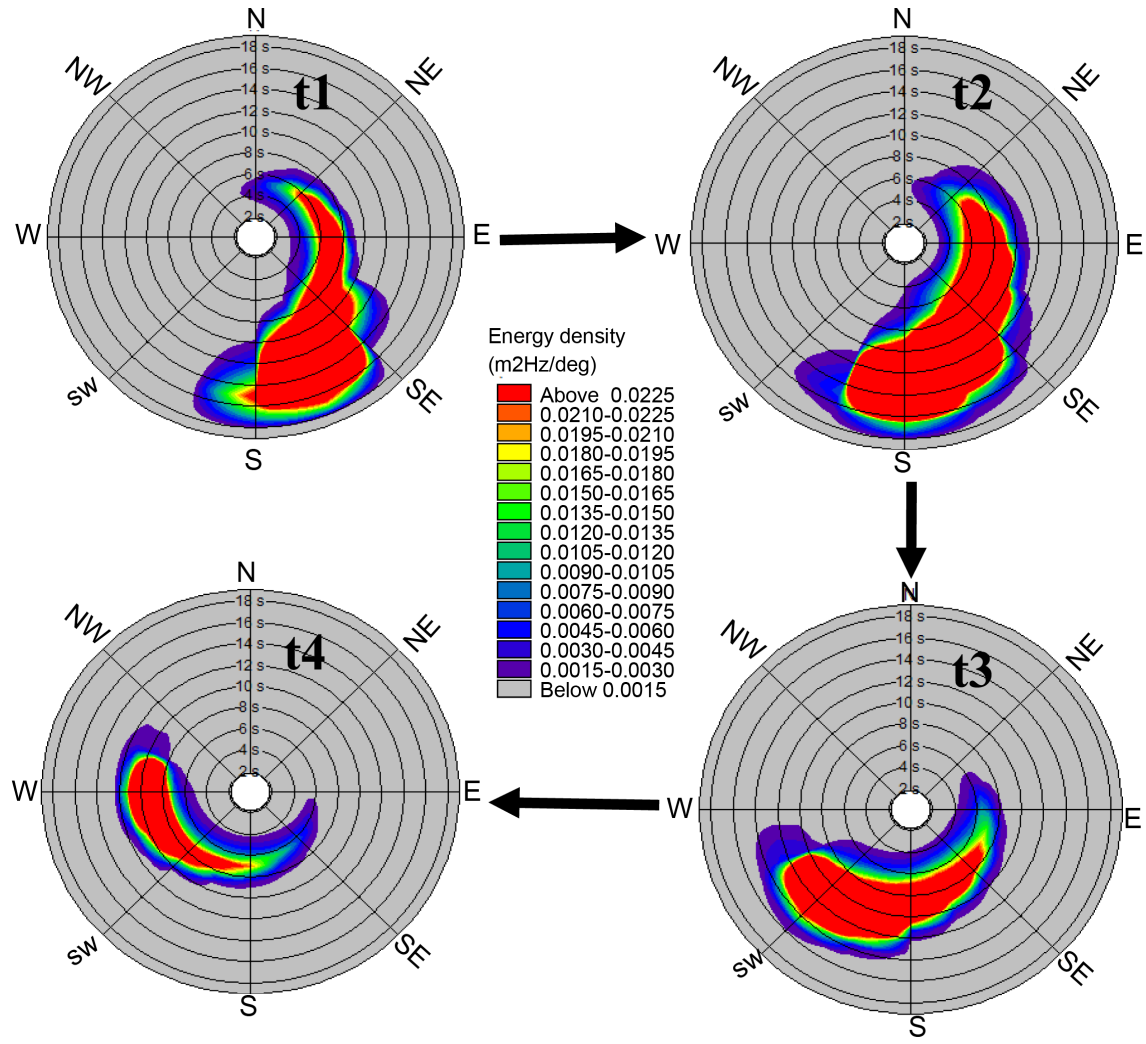

Figure 9. Simulated wave directional-frequency spectrum at station Off_Chab at times t1 to $t 4$. 
generated by the local Cyclone winds, the northeasterly energy portion is associated with lower periods which is the result of weakened Cyclone winds at the location of Off_Chab (see Figure 3 for the wind field). As the Cyclone progressed northwestward, more frequencies with larger amounts of energy contributed to the spectrum (time t2, Figure 9). At this time, due to intense Cyclone winds at Off_Chab, periods corresponding to the local wave energy (energy from north to northeast directions) reached to an upper limit of 10 seconds, while the directional range of the spectrum was more or less similar to time t1. The spectral frequency range at this location substantially shrank due to the landfall on the Oman Peninsula that occurred a few hours before time t3. At time t4, about 3 hours before the final landfall, the spectral frequency band included only energies between periods of 2 and 12 seconds. Similar to AW2, spectral energy directions rotated clockwise as the Cyclone proceeded northwestward.

\subsection{Frequency Spectra}

The spectral pattern produced by Gonu are further investigated by examining the frequency spectra at times $\mathrm{t} 1$ to $\mathrm{t} 4$ for stations AW2 and Off_Chab (Figure 10). The spectra were obtained by integrating the $2 \mathrm{D}$ directional-frequency spectra discussed above with respect to direction. The 1-D spectra at these two locations generally show single energy peaks at low frequencies. However, energy peaks and peak frequencies were different at different times. For both locations, peaks of energy were observed at time $\mathrm{t} 3$, while time $\mathrm{t} 4$ corresponded to the lowest energy peaks. The smallest peak frequency occurred at time $\mathrm{t} 1$ for both locations. Time variations of spectral peaks for these locations can be described based on the data from the JONSWAP experiment (Hasselman et al. [5]) and the resulting JONSWAP spectral pattern. According to this experiment, the frequency spectrum for a sea with growing waves can be expressed based on the fetch length and wind speed along the fetch as follows:

$$
\begin{array}{r}
S(f)=\frac{\alpha g^{2}}{(2 \pi)^{4} f^{5}} \mathrm{e}^{-1.25\left(f_{m} / f\right)^{4}} \gamma^{a} \\
a=\mathrm{e}^{-\left[\left(f-f_{m}\right)^{2} /\left(2 \sigma^{2} f_{m}^{2}\right)\right]}
\end{array}
$$

where:

$$
\sigma=0.07 \text { when } f<f_{m}
$$
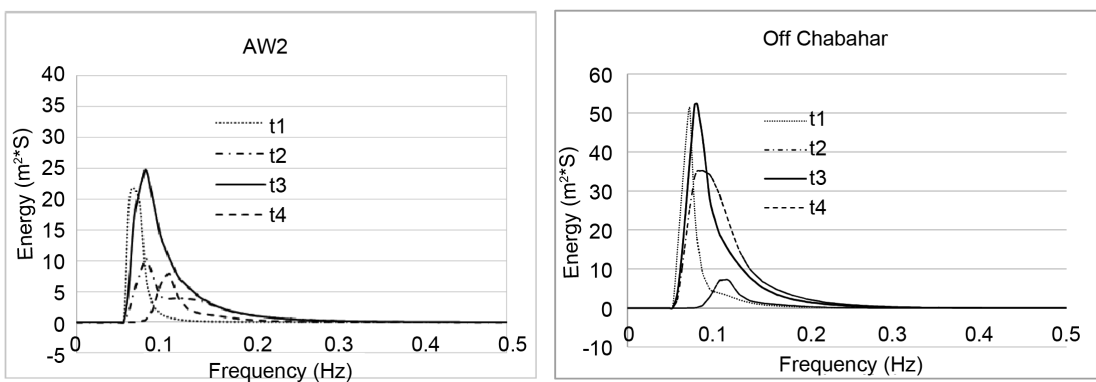

Figure 10. Simulated frequency spectra at AW2 and Off_chab at times t1 to t4. 


$$
\begin{gathered}
\sigma=0.09 \text { when } f \geq f_{m} \\
\alpha=0.076\left(\frac{g X}{U^{2}}\right)^{-0.22} \\
f_{m}=\frac{3.5 g}{U}\left(\frac{g X}{U^{2}}\right)^{-0.33} \\
\gamma=7\left(\frac{g X}{U^{2}}\right)^{-0.143}
\end{gathered}
$$

where $S(f)$ is the spectral wave energy as a function of frequency $f$ and $g$ is acceleration due to gravity. Parameter $\alpha$ denotes the equilibrium coefficient which is a function of the fetch length $X$ and wind speed $U$ along the fetch (Equation (13)), $\gamma$ is the peak parameter and represents the ratio of the spectral energy peak at a specific time to the fully developed sea spectral peak as presented by the Pierson-Moskowitz spectral pattern, and $f_{m}$ is the peak frequency which is calculated based on the fetch length $X$ and wind speed $U$ (Equation (14)). The peak parameter $\gamma$ is a criterion that shows the growth of the spectral peak with wind speed and fetches length. It is shown that the energy peak in a growing sea is a function of (Equation (15)). Hence, for stations AW2 and Off_Chab, the spectral peak evolution during Gonu can be described based on the peak parameter. However, it should be noted that the relationships for the spectral pattern and all associated parameters as presented by Hasselman et al. [5] are for non-cyclonic conditions with an almost constant wind direction along the wave fetch. Ochi [10] stated that the wave spectra resulting from measurements during hurricanes are different from those of ordinary storms. By comparing spectra of similar wind speeds from ordinary storms and hurricanes, he showed that for a cyclonegenerated spectrum, energy is more concentrated around the peak frequency and a narrower spectral range is observed. The least square fit analysis of hurricane spectral data on the JONSWAP spectrum by Ross [36] showed that the cyclone-generated spectrum follows the same spectral pattern of JONSWAP, but the peak frequency, peak parameter, and the equilibrium parameter should be modified based on the cyclone location and wind condition. He suggested the following relationships for these parameters:

$$
\begin{gathered}
\gamma=4.70 \bar{X}_{r}^{-0.13} \\
\alpha=0.035 \bar{f}_{m}^{0.82} \\
\bar{f}_{m}=0.97 \bar{X}_{r}^{-0.21} \\
\bar{f}_{m}=f_{m} U / g \\
\bar{X}_{r}=X_{r} g / U^{2}
\end{gathered}
$$

In these equations $X_{r}$ is the radial distance from the eye of hurricane and $U$ is the 10-meter wind speed above the sea surface.

Here, the modified forms of JONSWAP spectral parameters were used for estimating the peak parameter for both AW2 and Off_Chab stations. Equations (18) and (19) were used to calculate the values of the peak parameter at each lo- 
cation. Values of $\mathrm{X}$ and $\mathrm{U}$ for each location and at different times are presented in Table 1. The average wind speeds along the lines connecting each location to the instantaneous location of the eye are presented in the table and were used in calculation of the spectral peak parameter. Figure 11 shows the calculated values of the peak parameter at different times for both AW2 and Off_Chab. At each time step, the normalized value of the simulated spectral peak is shown. For both locations, the increasing trend of the spectral peak parameter is consistent with the increase of the simulated values of spectral energy (times $t 4$, $t 1$, and $t 3$ ). The trend at time $\mathrm{t} 2$ is different. While the largest spectral peaks among all time steps were simulated at $\mathrm{t} 2$, the estimated values for the peak parameter $\gamma$ were not the largest. It could be due to the significant variations of the wind speed and direction between the eye and the location of stations that violates the assumption of using an average wind speed for the calculation of the peak parameter.

The above analysis assumed that the JONSWAP spectrum with modifications suggested by Ross [36] is a valid spectral pattern during a cyclone. To evaluate this assumption, the JONSWAP spectrum calculated at station AW2 was compared with the simulated spectrum at a different time. The comparison result for time $\mathrm{t} 3$ is presented in Figure 12. The JONSWAP spectrum was calculated using Equations (11) and (12) with modified and $\gamma$ values based on Equations (16)-(20). Instead of using the semi-empirical Equation (19) for estimating fm, the value of the peak period measured by the buoy at AW2 was used. This is because inaccurate values for the peak frequency cause substantial discrepancies in the peak parameter and total energy of the spectrum (Allahdadi et al. [37]). Comparisons showed a good agreement between the JONSWAP and simulated spectra in terms of energy peaks, the general shape of spectrum, and the frequency domain contributing to the spectral shape. Compared to the JONSWAP spectrum, the energy for the simulated spectrum is more concentrated around the peak frequency.

\subsection{Directional Spectra}

In the analytical representation of the frequency-direction spectrum, energy is represented as the product of two functions:

$$
S(f, \theta)=S(f) G(f, \theta)
$$
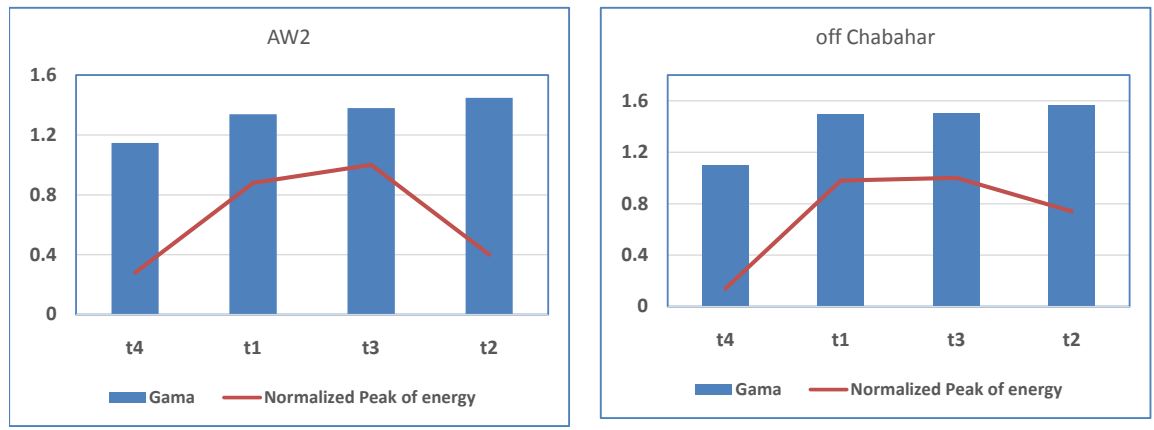

Figure 11. Variations of normalized peak frequency with the JONSWAP peak parameter $\gamma$ for stations AW2 and Off_chab. 


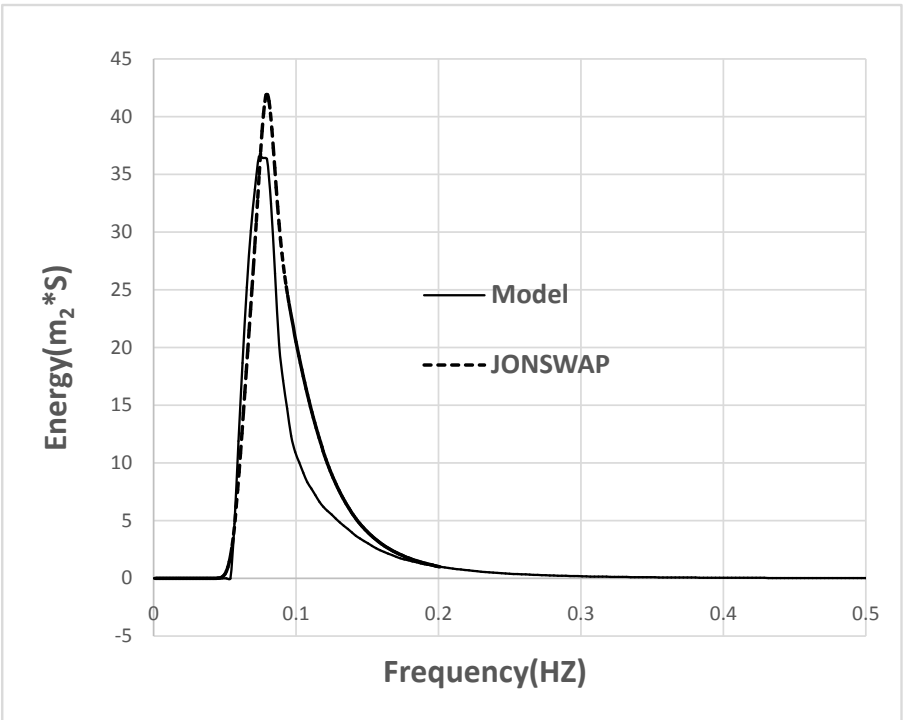

Figure 12. Comparison of simulated frequency spectrum at AW2 with hurricane modified JONSWAP spectrum at time $\mathrm{t} 3$.

in which $S(f)$ is the frequency spectrum function as discussed above and $G(\theta)$ is a directional spreading function that can be a function of frequency as well as direction. The analytic relationships suggested for the directional spreading function are mostly in the form of cosine functions that depict a symmetrical spreading around the peak wave direction (for example functions suggested by Mitsuyasu [6], Hasselman [7] and Donelan [8]. The functions were obtained based on the assumption of a uni-directional wind that results in the symmetrical shape of the function around the wind direction. During a cyclone, the complex spatially varying wind direction can cause significant asymmetry around the directional peak of the function. To examine this hypothesis, simulated wave energy spectra at AW2 and Off_Chab were integrated in the frequency domain to obtain the directional spectra at different times (Figure 13 and Figure 14). For AW2 at time t1, directional spreading was almost symmetrical around the peak of directional energy, while local wind direction showed a 120-degree difference from this direction. As the Cyclone proceeded northwestward, directional distributions exhibited a more asymmetrical pattern and smaller differences were observed between the local wind direction and the direction of the peak. The symmetrical pattern of directional spectra at time $t 1$ could be the result of weak local wind speeds compared to the remote winds, due to the large distance between AW2 and Cyclone Gonu's eye. At times when the eye was closer to the station, local wind speed increased and could significantly contribute to the directional energy spreading, although the energy peak was still produced by remote winds. At station Off_Chab, which was generally closer to Gonu's center, the directional spectrum at time $t 1$ was less symmetrical compared to that of AW2 at the same time. For other times, the directional spectra were highly asymmetrical, as the local wind contributed more to the spectral energy spreading. 

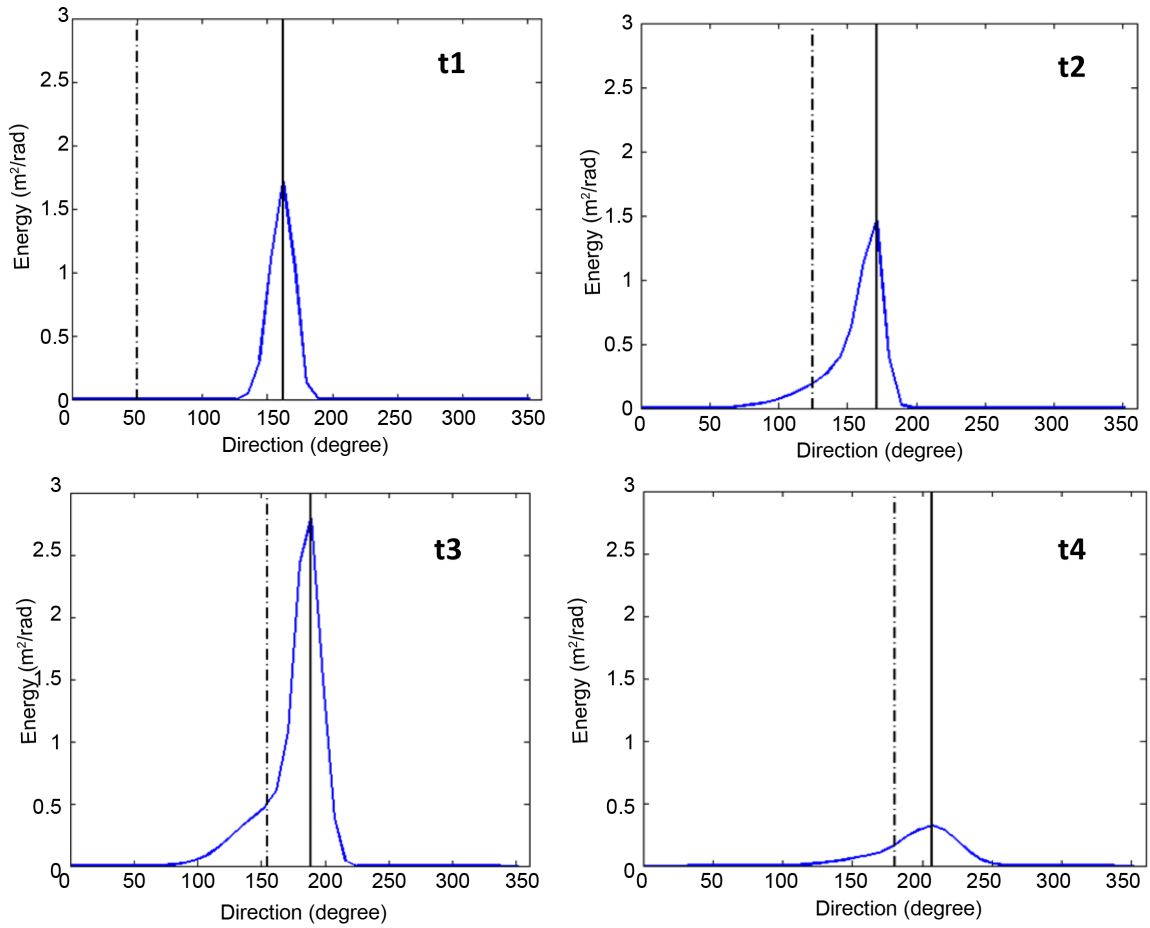

Figure 13. Simulated directional spectra at AW2 for times t1 to t4. The dashed vertical line shows the local wind direction at each time, while the solid vertical line represents the direction of energy peak in the spectrum.
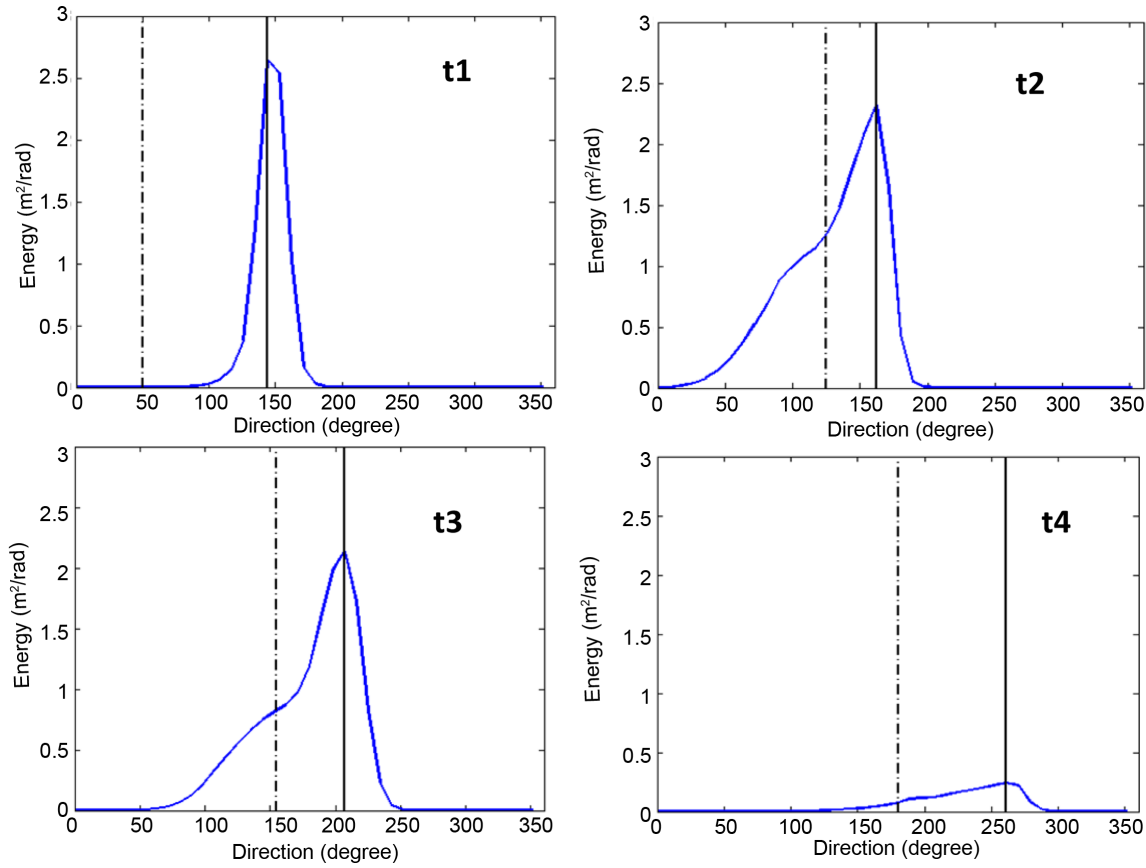

Figure 14. Simulated directional spectra at station Off_Chab for times t1 to t4.

\section{Summary and Conclusions}

Wave fields generated by Cyclone Gonu in the Arabian Sea and the northern

Oman Sea were simulated using Mike21-SW, which was forced by a cyclone 
wind field generated using the approach of Holland [25]. The model was employed to study the spectral variations of wave energy at two locations in the northern Oman Sea. Examination of the simulated frequency-direction spectra for these two relatively remote locations from Gonu's center showed that a wide directional spreading was produced. For both locations, the energy was distributed within a 100 - 180 degree band during different times of the Cyclone's translation northwestward. The range of energy spreading in the spectrum obtained from the present study can be used as a guide for selecting the optimum values of the spectral direction number in further simulations of cyclone-generated waves. Due to the clockwise rotation of the wind vector on the right side of the cyclone's eye in the Northern Hemisphere, spectral directions rotated clockwise as the cyclone progressed northwestward.

Frequency spectra at both stations generally followed the well-defined unimodal form of the JONSWAP spectrum with a designated peak in the lower frequency zone. The simulated spectral peaks at different times could be appropriately described by the peak parameter as defined by Hasselman et al. [5]) and modified for cyclone conditions by Ross [36]. Simulated frequency spectra were comparable with the spectra calculated using the modified JONSWAP. However, using the estimated peak frequency from either the original or the modified JONSWAP formulation resulted in unrealistic spectral peaks, which were significantly smaller than simulated values. Using the measured peak frequency in calculating the JONSWAP spectrum substantially enhanced the consistency between simulated and JONSWAP spectra.

Directional spectra at both locations were almost symmetrical around the peak of directional energy, in the case of weak local cyclone wind speeds at each station. As cyclone's eye progressed closer to the stations, the spectra became more asymmetrical. In all cases, the difference between the direction of the spectral peak and the local wind direction was considerable, although as the eye progressed closer to the stations, the differences decreased.

\section{Acknowledgements}

This research was supported by the Iranian Port and Maritime Organization through providing field data. N.F.T Company is acknowledged for providing the license for MIKE 21. The authors also would like to thank Mr. Amin Afshar the head of coastal engineering group at N.F.T for all of his support during the implementation of the research.

\section{References}

[1] Allahdadi, M.N., Jose, F., D’Sa, E.J. and Ko, D.S. (2017) Effect of Wind, River Discharge, and Outer-Shelf Phenomena on Circulation Dynamics of the Atchafalaya Bay and Shelf. Ocean Engineering, 129, 567-580.

[2] D’Sa, E.J., Roberts, H.H. and Allahdadi, M.N. (2011) Suspended Particulate Matter Dynamics along the Louisiana-Texas Coast from Satellite Observation. Proceedings of Coastal Sediments 2011, Miami, 2-6 May 2011, 2390-2402.

https://doi.org/10.1142/9789814355537_0179 
[3] Tehrani, N.C., D’Sa, E.J., Osburn, C.L., Bianchi, T.S. and Schaeffer, B.A. (2013) Chromophoric Dissolved Organic Matter and Dissolved Organic Carbon from SeaViewing Wide Field-of-View Sensor (SeaWiFS), Moderate Resolution Imaging Spectroradiometer (MODIS) and MERIS Sensors: Case Study for the Northern Gulf of Mexico. Remote Sensing, 5, 1439-1464. https://doi.org/10.3390/rs5031439

[4] Chaichitehrani, N. (2012) Investigation of Colored Dissolved Organic Matter and Dissolved Organic Carbon Using Combination of Ocean Color Data and Numerical Model in the Northern Gulf of Mexico. Master's Thesis, Louisiana State University, Baton Rouge.

[5] Hasselmann, K., et al. (1973) Measurements of Wind-Wave Growth and Swell Decay during the Joint North Sea Wave Project (JONSWAP). Erganzungsheft zur Deutschen Hydrographischen Zeitschrift Reihe A, A8, 1-95.

[6] Mitsuyasu, H., Tasai, F., Suhara, T., Mizuno, S., Ohkusu, M., Honda, T. and Rikiishi, K. (1975) Observations of the Directional Spectrum of Ocean Waves Using a Cloverleaf Buoy. Journal of Physical Oceanography, 5, 750-760. https://doi.org/10.1175/1520-0485(1975)005<0750:OOTDSO >2.0.CO;2

[7] Hasselmann, D.E., Dunckel, M. and Ewing, J.A. (1980) Directional Wave Spectra Observed during JONSWAP 1973. Journal of Physical Oceanography, 10, 12641280. https://doi.org/10.1175/1520-0485(1980)010<1264:DWSODJ>2.0.CO;2

[8] Donelan, M.A., Hamilton, J. and Hui, W.H. (1985) Directional Spectra of WindGenerated Waves. Philosophical Transactions of the Royal Society of London, 315, 509-562. https://doi.org/10.1098/rsta.1985.0054

[9] Whalen, J.E. and Ochi, M.K. (1978) Variability of Wave Spectral Shapes Associated with Hurricanes. Proceedings of the 10 th Offshore Technology Conference, Texas, USA. https://doi.org/10.4043/3228-MS

[10] Ochi, M.K. (1998) Ocean Waves: The Stochastic Approach. Cambridge University Press, Cambridge. https://doi.org/10.1017/CBO9780511529559

[11] Young, I.R. (2006) Directional Spectra of Hurricane Wind Waves. Journal of Geophysical Research: Oceans, 111, C08020. https://doi.org/10.1029/2006JC003540

[12] Walsh, E.J., Wright, C.W., Vandermark, D., et al. (2002) Hurricane Directional Wave Spectrum Spatial Variation at Landfall. Journal of Physical Oceanography, 32, 1667-1684. https://doi.org/10.1175/1520-0485(2002)032<1667:HDWSSV >2.0.CO;2

[13] Wright, C.W., Walsh, E.J., Vandermark, D., et al. (2001) Hurricane Directional Wave Spectrum Spatial Variation in the Open Ocean. Journal of Physical Oceanography, 31, 472-2488. https://doi.org/10.1175/1520-0485(2001)031<2472:HDWSSV>2.0.CO;2

[14] Moon, I., Ginis, I., Hara, T., Tolman, H., Wright, C.W. and Walsh, E.J. (2003) Numerical Simulation of Sea Surface Directional Wave Spectra under Hurricane Wind Forcing. Journal of Physical Oceanography, 33, 1680-1706. https://doi.org/10.1175/2410.1

[15] Prasad, K.B. and Stone, G.W. (2007) Numerical Simulation of Typhoon Wind Forcing in the Korean Seas Using a Spectral Wave Model. Journal of Coastal Research, 23, 362-373. https://doi.org/10.2112/04-0173.1

[16] Zhou, L., Wang, A. and Guo, P. (2008) Numerical Simulation of Sea Surface Directional Wave Spectra under Typhoon Wind Forcing. Journal of Hydrodynamics, 20, 776-783.

[17] Fan, Y., Ginis, I., Hara, T., Wright, C.W. and Walsh, E.J. (2009) Numerical Simulations and Observations of Surface Wave Fields under Extreme Tropical Cyclone. Journal of Physical Oceanography, 39, 2097-2116. 
https://doi.org/10.1175/2009JPO4224.1

[18] Kim, K.O., Yuk, J. and Choi, B.H. (2016) Simulation of Typhoon Bolaven Using Integrally Coupled Tide-Surge-Wave Models Based on Locally Enhanced Fine-Mesh Unstructured Grid System. Journal of Coastal Research, Special Issue 75, 11271131. https://doi.org/10.2112/SI75-226.1

[19] Najar, K.A. and Salvekar, P.S. (2010) Understanding the tropical Cyclone Gonu. In: Charabi, Y., Ed., Indian Ocean Tropical Cyclones and Climate Change, Springer, The Netherlands, 359-369. https://doi.org/10.1007/978-90-481-3109-9_40

[20] Mashhadi, L., Hadjizadeh Zaker, N., Soltanpour, M. and Moghimi, S. (2015) Study of the Gonu Tropical Cyclone in the Arabian Sea. Journal of Coastal Research, 31, 616-623. https://doi.org/10.2112/JCOASTRES-D-13-00017.1

[21] Fritz, H.M., Blount, C.D., Albusaidi, F.B. and Al-Harthy, A.H.M. (2010) Cyclone Gonu Storm Surge in Oman. Estuarine, Coastal and Shelf Science, 86, 102-106.

[22] Krishna, K.M and Rao, S.R. (2009) Study of the Intensity of Super Cyclonic Storm GONU Using Satellite Observations. International Journal of Applied Earth Observation and Geoinformation, 11, 108-113.

[23] Dibajnia, M., Soltanpour, M., Nairn, R. and Allahyar, M. (2010) Cyclone Gonu: The Most Intense Tropical Cyclone on Record in the Arabian Sea. In: Charabi, Y., Ed., Indian Ocean Tropical Cyclones and Climate Change, Springer, The Netherlands, 149-157. https://doi.org/10.1007/978-90-481-3109-9_19

[24] Wang, Z., DiMarco, S.F., Stossel, M.M., Zhang, X., Howard, M.K. and Vall, K. (2012) Oscillation Responses to Tropical Cyclone Gonu in Northern Arabian Sea from a Moored Observing System. Deep Sea Research, Part I, 64, 129-145.

[25] Holland, G.J. (1980) An Analytic Model of the Wind and Pressure Profiles in Hurricanes. Monthly Weather Review, 108, 1212-1218. https://doi.org/10.1175/1520-0493(1980)108<1212:AAMOTW >2.0.CO;2

[26] Young, I.R. and Sobey, R.J. (1981) The Numerical Prediction of Tropical Cyclone Wind-Waves. James Cook University of North Queensland, Townville, Department of Civil \& Systems Engineering, Research Bulletin No. CS20.

[27] Phadke, A.C., Martinoa, C.D., Cheung, K.F. and Houston, S.H. (2003) Modeling of Tropical Cyclone Winds and Waves for Emergency Management. Ocean Engineering, 4, 553-578.

[28] Rego, J.L. and Li, C. (2009) On the Receding of Storm Surge along Louisiana's Low-Lying Coast. Journal of Coastal Research, Special Issue No. 56, 1045-1049.

[29] Rego, J.L. and Li, C. (2010) Storm Surge Propagation in Galveston Bay during Hurricane Ike. Journal of Marine Systems, 82, 265-279.

[30] Allahdadi, M. (2015) Numerical Experiments of Hurricane Impact on Vertical Mixing and Restratification of the Louisiana Shelf. Ph.D. Dissertation, Louisiana State University, Baton Rouge.

[31] Willoughby, H.F. and Rahn, M.E. (2004) Parametric Representation of the Primary Hurricane Vortex. Part I: Observations and Evaluation of the Holland (1980) Model. Monthly Weather Review, 132, 3033-3048. https://doi.org/10.1175/MWR2831.1

[32] DHI Water and Environment (2015) Mike 21-SW, User Manual.

[33] WAMDI Group (1988) The WAM Model-A Third Generation Ocean Wave Prediction Model. Journal of Physical Oceanography, 18, 1775-1810. https://doi.org/10.1175/1520-0485(1988)018<1775:TWMTGO >2.0.CO;2

[34] Komen, G.L., Cavaleri, L., Donelan, M., Hasselmann, K., Hasselmann, S. and Janssen, P.A.E.M. (1994) Dynamics and Modelling of Ocean Waves. Cambridge Uni- 
versity Press, New York.

[35] Allahdadi, M.N. Chegini, V., Fotouhi, N. and Golshani, A. (2004) Wave Modeling and Hindcast of the Caspian Sea. Proceedings of the 6 th International Conference on Coasts, Ports, and Marine Structures, Tehran, Iran.

[36] Ross, D.B. (1979) Observing and Predicting Hurricane Wind and Wave Conditions. Proceedings of the Joint IOC/ WMO Seminar on Oceanographic Products and the IGOSS Data Processing and Services System, Moscow.

[37] Allahdadi, M.N., Fotouhi, N. and Taebi, S. (2004) Investigation of Governing Wave Spectral Pattern near Anzali Port Using Measured Data. Proceedings of the 6 th International Conference on Coasts, Ports, and Marine Structures, Tehran, Iran.

Submit or recommend next manuscript to SCIRP and we will provide best service for you:

Accepting pre-submission inquiries through Email, Facebook, LinkedIn, Twitter, etc. A wide selection of journals (inclusive of 9 subjects, more than 200 journals)

Providing 24-hour high-quality service

User-friendly online submission system

Fair and swift peer-review system

Efficient typesetting and proofreading procedure

Display of the result of downloads and visits, as well as the number of cited articles Maximum dissemination of your research work

Submit your manuscript at: http://papersubmission.scirp.org/

Or contact ojfd@scirp.org 